\title{
Optimal Reserves in Financially Closed Economies
}




\section{WP/16/92}

\section{IMF Working Paper}

\section{Optimal Reserves in Financially Closed Economies}

by Olivier Jeanne and Damiano Sandri

IMF Working Papers describe research in progress by the author(s) and are published to elicit comments and to encourage debate. The views expressed in IMF Working Papers are those of the author(s) and do not necessarily represent the views of the IMF, its Executive Board, or IMF management.

\section{N T E R N A T I O N A L MONETAR Y F U N D}




\title{
IMF Working Paper
}

Research Department

\section{Optimal Reserves in Financial Closed Economies ${ }^{1}$}

Prepared by Olivier Jeanne and Damiano Sandri

Authorized for distribution by Maria Soledad Martinez Peria

April 2016

IMF Working Papers describe research in progress by the author(s) and are published to elicit comments and to encourage debate. The views expressed in IMF Working Papers are those of the author(s) and do not necessarily represent the views of the IMF, its Executive Board, or IMF management.

\begin{abstract}
Financially closed economies insure themselves against current-account shocks using international reserves. We characterize the optimal management of reserves using an open-economy model of precautionary savings and emphasize several results. First, the welfare-based opportunity cost of reserves differs from the measures often used by practitioners. Second, under plausible calibrations the model is consistent with the rule of thumb that reserves should be close to three months of imports. Third, simple linear rules can capture most of the welfare gains from optimal reserve management. Fourth, policymakers should place more emphasis on how to use reserves in response to shocks than on the reserve target itself.
\end{abstract}

JEL Classification Numbers: F32, F41

Keywords: Official reserves, current account, precautionary savings

Author’s E-Mail Address: ojeanne@jhu.edu , dsandri@imf.org

${ }^{1}$ This paper was written while Olivier Jeanne was visiting the Research Department of the IMF, whose hospitality is gratefully acknowledged. We thank Joshua Aizenman, Anton Korinek, Jonathan Ostry and Chris Otrok for helpful comments, as well as seminar participants at the 2016 AEA meetings (San Francisco) and the IMF. 


\section{Contents}

1 Introduction $\underline{3}$

2 A model of optimal reserves management $\underline{6}$

2.1 Model structure . . . . . . . . . . . . . . . . . . . $\underline{6}$

2.2 Carry cost and the target level of reserves . . . . . . . . . $\underline{8}$

3 Calibration $\quad \underline{12}$

4 Quantitative Results $\quad \underline{15}$

4.1 Target and average levels of reserves . . . . . . . . . . $\underline{15}$

4.2 Impulse response functions . . . . . . . . . . . . . . . . . . . $\underline{17}$

4.3 Linear rules . . . . . . . . . . . . . . . . . . . . . . . . $\underline{19}$

5 Conclusion $\quad \underline{23}$

6 Appendix: Certainty Equivalence $\quad \underline{25}$ 


\section{Introduction}

One question of considerable practical relevance for international economists is the appropriate level of international reserves (IMF, 2011, 2013, 2015). In this paper we study this question in the context of a model where reserves play a very simple and basic role of precautionary savings against current account shocks. To simplify the analysis we study the case of a small open economy that insures against current account shocks with international reserves only. This case is applicable, at least as an approximation, to countries in which the private sector cannot insure itself directly because it has little access to international financial markets. This situation was more prevalent under the Bretton Woods system than today, but it remains relevant for developing countries with the lowest levels of international financial integration.

We study the question of the optimal management of reserves using an intertemporal optimizing model of an open economy populated by an infinitely-lived representative consumer. The consumer consumes nontradable goods and imported goods. The economy is hit by shocks to the value of exports in terms of imports (which might come from shocks to the quantity of exports or to the terms of trade). The consumer holds claims against the domestic government, but does not have access to international financial markets. The government issues domestic bonds and holds international reserves, i.e., bonds denominated in foreign currency. Reserves are foreign assets that are held by the government on behalf of the domestic consumer.

We assume that the government is benevolent and manages reserves to maximize domestic welfare. Reserves allow the country to smooth imports in response to shocks to the value of its exports in terms of imports. The optimal amount of reserves is the consumer's optimal level of precautionary savings in response to export income shocks. This is the type of thinking that underpinned old rules of thumb such as "reserves should cover three months of imports".

We show that in the model the level of reserves tends to converge toward a target and characterize how this target depends on the parameter values. The influence of several parameters is summarized in a key variable, which we call the "carry cost" of reserves. The carry cost is the difference between the hypothetical real interest rate that would prevail under financial autarky in the deterministic steady-growth path and the real return on reserves in terms of imports. Measuring the carry cost as a spread between two interest rates is reminiscent of the way that the cost of holding 
reserves is measured in the existing literature on international reserves, but there are important differences. In particular, the carry cost is not the same as two measures that are often used by practitioners, the quasi-fiscal cost of holding reserves for the central bank, and the spread between the cost of external borrowing and the return on reserves. The carry cost is a theoretical construct that involves a counterfactual interest rate that is not observed in the data.

We then calibrate our model using data on a sample of 21 developing countries from 1960 to 2014. We select countries that were not very internationally financially integrated and so for which the current account was arguably the main source of shocks. Our benchmark calibration implies a carry cost equal to 6.9 percent, and a target level of reserves equal to 3.3 months of imports, remarkably close to the conventional three-months-of-imports rule of thumb. Furthermore, the model predicts a stochastic distribution of reserves whose average is very close to the average level of reserves in our sample, about 4.5 months of imports.

The model predictions are however sensitive to the carry cost. In particular, the optimal level of reserves goes to infinity as the carry cost goes to zero. This result is not surprising from the point of view of the literature on precautionary savings, but it implies that it may be difficult in general to determine whether an observed level of reserves is "excessive" based on a precautionary savings model. However we find that if the consumer's discount factor is lower than 1 it is difficult to rationalize a carry cost under 5 percent for the countries in our sample.

The policy function for reserves prescribed by the model is non-linear and therefore cannot easily guide the actions of policy makers. We thus investigate the extent to which the gains from optimal reserves management can be reaped using simple linear rules. We find that the optimal policy function is well approximated by a linear rule that makes reserves respond to export income shocks in the short run and converge towards a target in the long run. This rule can indeed yield more than 90 percent of the welfare gains from optimal reserves management. We observe that under this rule reserves respond significantly less to export income shocks than under certainty equivalence. Furthermore, the optimal weight put on convergence is not negligible since it implies that a deviation from the target has a half-life of about three years.

We also assess the robustness of our linear rule to errors in the reserve target or in the parameters controlling how reserves respond to shocks. While practitioners have been mostly concerned about identifying an optimal target for reserves, we show that 
this target has actually limited consequences for welfare. Much more important is to adopt policy rules that optimally smooth consumption in response to shocks. In particular, the optimal rule implies significant and prolonged departures of reserves from the target in response to shocks.

Literature. The paper is related to the literature on the optimal level of reserves for an open economy. The cost-benefit approach to the optimal level of reserves has inspired a long line of literature going back at least to Heller (1966). In Heller's analysis the optimal level of reserves was determined in the context of a trade-off between their opportunity cost and the risk of an external disequilibrium leading to a costly contraction in domestic absorption. ${ }^{1}$ More recently calibrated models include Jeanne (2007) or Jeanne and Rancière (2011). ${ }^{2}$ Here we compare the implications of a precautionary savings model to the heuristic measures of the benefits and costs of reserves that have been used in the empirical or policy literature (IMF, 2011, 2013, 2015).

The paper is also related to the question of how to make foreign assets stationary in stochastic models of the current account. Linearizing a stochastic model of a small open economy leads to nonstationarity of foreign assets, in contradiction with the maintained assumption that the economy should stay close to a steady state. Many authors solve this problem by using the assumptions reviewed by Schmitt-Grohé and Uribe (2003) to make foreign assets stationary. As noted by Coeurdacier, Rey and Winant (2011) another way of making foreign assets stationary is to solve for the equilibrium with precautionary savings, as we do here. We show that the best linear rules are rather different from the equilibrium policies derived from linearizing models a la Schmitt-Grohé and Uribe (2003): significantly more weight is put on convergence towards the target and significantly less weight is put on smoothing.

This paper contributes to the literature on precautionary saving in the open economy. ${ }^{3}$ One branch of this literature tries to explain global imbalances and upstream

\footnotetext{
${ }^{1}$ The dynamic aspect of the authorities' optimization problem was treated more rigorously in the buffer stock models of international reserves of Hamada and Ueda (1977) and Frenkel and Jovanovic (1981).

${ }^{2}$ However these contributions are not based on fully dynamics precautionary savings models. In Jeanne and Rancière (2011) reserves contracts involve transfers that are contingent on the occurrence of shocks.

${ }^{3}$ There is a long line of literature on precautionary savings against income shocks that we draw on. This literature is too vast to be reviewed here, see Heathcote, Storesletten and Violante, 2009 for a review.
} 
capital flows from developing to advanced economies. Some papers look at precautionary savings in response to idiosyncratic income shocks (Carroll and Jeanne, 2009; Angeletos and Panousi, 2011; Sandri, 2014). Other papers, like this one, consider aggregate income shocks (Ghosh and Ostry, 1997; Durdu, Mendoza and Terrones, 2009; Fogli and Perri, 2015; Kent, 2015).

\section{A model of optimal reserves management}

We present the assumptions of the model (section 2.1) and then derive analytical results about the optimal level of reserves (section 2.2).

\subsection{Model structure}

The economy is populated by a unitary mass of identical atomistic consumers and a government. The representative consumer maximizes,

$$
U_{t}=E_{t}\left[\sum_{s=0}^{+\infty} \beta^{s} u\left(C_{t+s}\right)\right],
$$

with

$$
u\left(C_{t}\right)=\frac{C_{t}^{1-\gamma}-1}{1-\gamma},
$$

and

$$
C_{t}=\left[\alpha^{1 / \eta} M_{t}^{(\eta-1) / \eta}+(1-\alpha)^{1 / \eta} N_{t}^{(\eta-1) / \eta}\right]^{\eta /(\eta-1)},
$$

where $M_{t}$ is the consumption of imported good and $N_{t}$ is the consumption of nontraded good.

We write the budget constraints in terms of a foreign currency, which for the sake of concreteness we call the dollar. The representative consumer's budget constraint is,

$$
\frac{B_{t}^{g}}{\mathscr{E}_{t}}+P_{M t} M_{t}=P_{X t} X_{t}+\frac{\left(1+i_{t-1}^{g}\right) B_{t-1}^{g}}{\mathscr{E}_{t}}+T_{t},
$$

where $X_{t}$ and $M_{t}$ are respectively the quantities of exports and imports, and $P_{X t}$ and $P_{M t}$ are their dollar prices, $B_{t}^{g}$ is government debt expressed in terms of domestic currency and $\mathscr{E}_{t}$ is the domestic currency per dollar exchange rate, $i_{t-1}^{g}$ is the domestic currency interest rate and $T_{t}$ is a lump-sum transfer from the government. The 
representative consumer does not have access to foreign assets and can invest only in the liabilities of the domestic government.

The government budget constraint is,

$$
\frac{\left(1+i_{t-1}^{g}\right) B_{t-1}^{g}}{\mathscr{E}_{t}}+B_{t}+T_{t}=\frac{B_{t}^{g}}{\mathscr{E}_{t}}+\left(1+i_{t-1}\right) B_{t-1},
$$

where $B_{t}$ is the amount of dollar reserves, and $i_{t-1}$ is the dollar nominal interest rate.

The government includes the central bank. The government can engage in "open market" operations in which it changes its holdings of reserves and the outstanding stock of domestic bonds by the same amounts. The words "open market" are in quotes because the market is not really open: the domestic bonds must be purchased by residents who do not have access to foreign assets. A sterilized foreign exchange intervention in which the central bank sells government debt (or sterilization bonds) to buy reserves corresponds, in our model, to a simultaneous increase in $B_{t}$ and $B_{t}^{g}$.

The two budget constraints can be consolidated into the current account balance identity,

$$
B_{t}-B_{t-1}=P_{X t} X_{t}-P_{M t} M_{t}+i_{t-1} B_{t-1}
$$

There are exogenous processes for the value of exports $P_{X t} X_{t}$, the price of imports $P_{M t}$, the output of nontradable good $N_{t}$, and the dollar nominal interest rate $i_{t-1}$. The imports $M_{t}$ and reserves $B_{t}$ are endogenous.

We assume that there is a trend growth factor $G$ in income. We denote in lower case the detrended variables expressed in terms of imports (except for the consumption of nontradable good and total consumption, which are simply detrended):

$$
\begin{aligned}
m_{t} & =G^{-t} M_{t} \\
x_{t} & =G^{-t} P_{X t} X_{t} / P_{M t} \\
n_{t} & =G^{-t} N_{t} \\
b_{t} & =G^{-t} B_{t} / P_{M t} \\
c_{t} & =G^{-t} C_{t}
\end{aligned}
$$

The country's aggregate budget constraint can then be written in normalized form 
as

$$
b_{t}+m_{t}=\frac{1+r_{t}}{G} b_{t-1}+x_{t}
$$

where $r_{t}$ denotes the imported goods own real rate of interest between period $t-1$ and period $t$,

$$
1+r_{t}=\frac{1+i_{t-1}}{1+\pi_{t}}
$$

with the rate of inflation in imported goods denoted by $\pi_{t}=P_{M t} / P_{M t-1}-1$.

We assume that the level of reserves must be positive,

$$
b_{t} \geq 0
$$

If the constraint $b_{t} \geq 0$ is not binding the first-order condition for consumption is,

$$
u^{\prime}\left(C_{t}\right) \frac{\partial C_{t}}{\partial M_{t}}=\beta E_{t}\left[\left(1+r_{t+1}\right) u^{\prime}\left(C_{t+1}\right) \frac{\partial C_{t+1}}{\partial M_{t+1}}\right] \text {, }
$$

or, after detrending,

$$
c_{t}^{1 / \eta-\gamma} m_{t}^{-1 / \eta}=\beta G^{-\gamma} E_{t}\left[\left(1+r_{t+1}\right) c_{t+1}^{1 / \eta-\gamma} m_{t+1}^{-1 / \eta}\right] .
$$

The equilibrium is driven by exogenous stochastic processes for $x_{t}, n_{t}$, and $r_{t}$, which are assumed to be stationary and Markov. The state at time $t$, thus, is summarized by the current values of these variables and the level of reserves accumulated in the previous period, $s_{t}=\left(x_{t}, n_{t}, r_{t}, b_{t-1}\right)$. The equilibrium is characterized by endogenous policy functions for total consumption, imports and reserves, $c\left(s_{t}\right), m\left(s_{t}\right)$ and $b\left(s_{t}\right)$. The policy functions satisfy $(3)$ and

$$
c\left(s_{t}\right)=\left[\alpha^{1 / \eta} m\left(s_{t}\right)^{(\eta-1) / \eta}+(1-\alpha)^{1 / \eta} n_{t}^{(\eta-1) / \eta}\right]^{\eta /(\eta-1)} .
$$

\subsection{Carry cost and the target level of reserves}

As shown by Carroll (2009) in the context of a similar model, if the following condition holds

$$
\frac{G^{\gamma}}{\beta}>1+\bar{r}
$$

the level of reserves $b_{t}$ tends to fluctuate around a "target" level, $b^{*}$. This is the long-run level that reserves converge to in the absence of shocks, i.e. assuming that 
$x_{t}, n_{t}$, and $r_{t}$ remain equal to their average levels $\bar{x}, \bar{n}$, and $\bar{r}$ in the stochastic model. In other words, shock realizations generate a stochastic dispersion of reserves, but the model policy function attempts to bring the level of reserves back to the target $b^{*}$.

To understand condition (4), it is useful to define the "carry cost" of reserves as,

$$
\delta=\frac{G^{\gamma}}{\beta}-(1+\bar{r})
$$

The first term $G^{\gamma} / \beta$ is equal to the interest rate that would prevail under financial autarky in the deterministic steady-growth path. This is also the interest rate at which the representative consumer would be indifferent between borrowing or saving in a deterministic version of the model. The second term is the rate of return that the consumer earns on reserves.

Condition (4) requires the carry cost to be positive. Assume that the carry cost is actually zero. In this case, the return on reserves is high enough to make the consumer indifferent between borrowing and saving in the deterministic steady-growth path. In other words, there is no opportunity cost associated with accumulating reserves. Precautionary motives would then induce the representative consumer to accumulate an unbounded level of reserves. If instead the carry cost is positive, accumulating reserves entails an opportunity cost that ensures a finite target level.

The carry cost is a key variable that summarizes the combined effects of the discount factor, the growth rate and the elasticity of intertemporal substitution of consumption on the consumer's willingness to borrow against future income. The first-order condition (3) can be rewritten,

$$
c_{t}^{1 / \eta-\gamma} m_{t}^{-1 / \eta}=\frac{1}{1+\delta /(1+\bar{r})} E_{t}\left[\frac{1+r_{t+1}}{1+\bar{r}} c_{t+1}^{1 / \eta-\gamma} m_{t+1}^{-1 / \eta}\right] .
$$

Thus $\delta$ summarizes all we need to know about $\beta$ and $G$ in the Euler equation. Because $G$ appears in the budget constraint we keep it as a separate parameter but we will treat the carry cost $\delta$ instead of the discount factor $\beta$ as the exogenous parameter.

Our definition of the carry cost is reminiscent of how the opportunity cost of reserves is defined and measured in the literature, but there are interesting differences. First, the opportunity cost of reserves is often measured as the quasi-fiscal cost of accumulating reserves for the central bank, measured as the spread between the cost of issuing sterilization bonds - generally denominated in domestic currency - and the 
return on reserves (Frenkel and Jovanovic, 1981; Flood and Marion, 2001). In the model this quasi-fiscal cost can be written as the difference between the interest rate paid on the domestic debt securities and the return on the reserves,

$$
\left(1+i_{t}^{g}\right) \frac{\mathscr{E}_{t}}{\mathscr{E}_{t+1}}-\left(1+i_{t}\right)
$$

Note that for consistency the two interest rates must be expressed in the same currency. In (6) this currency is the dollar, which implies that the local currency interest rate must be adjusted for depreciation.

The first-order condition for the consumer's holding of government debt is,

$$
c_{t}^{1 / \eta-\gamma} m_{t}^{-1 / \eta}=\beta G^{-\gamma} E_{t}\left[\frac{1+i_{t}^{g}}{1+\pi_{t+1}} \frac{\mathscr{E}_{t}}{\mathscr{E}_{t+1}} c_{t+1}^{1 / \eta-\gamma} m_{t+1}^{-1 / \eta}\right]
$$

Assume for a moment that there is no exchange rate uncertainty one period ahead, i.e., $\mathscr{E}_{t+1}$ is know in period $t$. Then comparing (3) and (7) shows that uncovered interest parity applies,

$$
1+i_{t}=\left(1+i_{t}^{g}\right) \frac{\mathscr{E}_{t}}{\mathscr{E}_{t+1}}
$$

This implies that the quasi-fiscal cost given by (6) is equal to zero. Importantly, the reason that uncovered interest parity applies is not arbitrage by private agents (since the market for domestic bonds is completely insulated from the market for foreign bonds) but the optimizing behavior of the government. The government invests the reserves on behalf of the consumers and should reproduce the same allocation as in the equilibrium with perfect financial integration. Hence the government should ensure that the private sector receives the same real return on domestic securities as it would on foreign securities, which implies that there is no quasi-fiscal cost of holding reserves. A positive quasi-fiscal cost arises only if the government accumulates more reserves than the private sector would under perfect financial integration.

This argument does not apply however if there is exchange rate risk. In this case there will in general be a wedge in condition (6) that comes from the exchange rate risk premium. In general the domestic interest rate could be higher or lower than the level implied by uncovered interest parity, and if it is higher there is a quasi-fiscal cost of holding the reserves. ${ }^{4}$

\footnotetext{
${ }^{4}$ There might be other reasons outside of the model for which the government might be willing to incur a quasi-fiscal cost for holding reserves, for example if depreciating the domestic currency
} 
Irrespective of whether or not the government incurs a quasi-fiscal cost for holding the reserves, this cost is not an appropriate measure of the welfare cost of reserves for the country as a whole. In general the quasi-fiscal cost given by (6) has no reason to be equal to the carry $\operatorname{cost} \delta$. The main reason is that the quasi-fiscal cost is a cost for the government but a gain for the holders of domestic bonds, who are domestic residents. The counterpart of the fact that the government receives a lower return on the reserves than the interest rate it pays on its debt is that the private sector receives a higher return on its assets than if it directly held the reserves. The quasi-fiscal cost, thus, can be viewed as a transfer to the private sector that the government would not have to pay if it mandated the private sector to directly hold the reserves, for example through liquidity regulation. It is not a welfare cost for the country as a whole.

Another measure of the cost of reserves that is often used in the literature is the difference between the interest rate on external debt and the return on reserves. ${ }^{5}$ This does not coincide with the carry cost as defined in equation (5) because there is no presumption in general that a credit-constrained borrower pays the interest rate that makes him willing to borrow the constrained amount. For example in many models of international capital flows a credit-constrained open economy pays the riskless interest rate on its external borrowing because of perfect competition between lenders and the absence of default risk. In this case the difference between the external cost of borrowing and the return on reserves underestimates the true cost of holding reserves. The external cost of borrowing may include a default risk premium but it is not true in general that it should be included in the carry cost of reserves (Jeanne, 2007).

To summarize, the carry cost given by (5) is a theoretical construct that is not directly observable using market data because it involves a counterfactual interest rate, the interest rate that would be observed in the autarkic steady-growth path. In our calibration the carry cost will result from the values assigned to fundamental preference parameters such as the consumer's discount factor and risk aversion.

A final note of caution is that one should not confuse the target level of reserves with the average level of reserves. The unconditional average level of reserves based on stochastic simulations, $E(b)$, is in general higher than the target $b^{*}$. One reason is the concavity in the policy function, which implies that reserves converge towards the target at a faster pace when they are below target than when they are above

has welfare benefits. See Korinek and Serven (2010), Rabe (2013), Michaud and Rothert (2014).

${ }^{5}$ See for example Edwards (1985), Rodrik (2006), Hauner (2006). 
target. The zero-bound on reserves is another reason for this result. For example, if the target level of reserves is equal to zero the average level will be strictly higher than zero simply because the level of reserves cannot be negative.

\section{Calibration}

The model is calibrated to a group of developing countries that receive relatively little private capital flows. Our country sample has all the countries in the World Bank's World Development Indicators (WDI) database such that (i) long-term Public or Publicly-Guaranteed (PPG) debt represents at least 75 percent of their total external debt; (ii) they are not classified as fragile states in IMF (2014); and (iii) they have at least 15 consecutive years of data. The first condition ensures that the countries in our sample have a relatively low exposure to financial account shocks. The second condition was imposed because we found the quality of the data to be low in fragile states, and the last condition ensures that we have enough data to estimate the exogenous stochastic processes. The resulting sample includes 21 countries: Bangladesh, Benin, Botswana, Burkina Faso, Egypt, Ethiopia, Gabon, The Gambia, Kenya, Lesotho, Mauritania, Morocco, Mozambique, Namibia, Nigeria, Pakistan, Panama, Rwanda, Senegal, Sri Lanka, Uganda. The data are annual from 1960 to 2014.

The WDI database provides volume and value indexes for both exports and imports. These indexes give us respectively $\left\{X_{t}, M_{t}\right\}$ and $\left\{P_{X t} X_{t}, P_{M t} M_{t}\right\}$, conditional on initial values. By dividing import values by import volumes we can infer a price index $P_{M t}$ that we use to express export values in units of imports, $P_{X t} X_{t} / P_{M t}$. The WDI also provides series for exports and GDP in constant local currency units. Using the identity $G D P_{t}^{r}=P_{X} X_{t}+P_{N} N_{t}$, where $G D P_{t}^{r}$ is real GDP in year $t$ and the prices $P_{X}$ and $P_{N}$ are constant, we construct an index for nontradable output $N_{t}$ by subtracting gross real exports from real GDP. We then detrend exports (expressed in units of imports) and nontradable output to obtain indexes that measure the time variations in $x_{t}$ and $n_{t}$.

In order to calibrate the model we need levels (and not only first-differences) for the series $x_{t}$ and $n_{t}$. Since the model is homogeneous of degree 1 in $x_{t}$ and $n_{t}$, we can normalize $n_{t}$ so that its average value is equal to 1 for each country. The only piece of information that we then need to derive the whole path $x_{t}$ is the ratio $n / x$ in a given year. For this we divide the identity for nominal GDP, $G D P_{t}=P_{X t} X_{t}+P_{N t} N_{t}$ 
by the nominal value of exports $P_{X t} X_{t}$ to obtain,

$$
\frac{G D P_{t}}{P_{X t} X_{t}}=1+\frac{n_{t}}{x_{t}} \frac{P_{N t}}{P_{M t}} .
$$

We assume that the quantity of imported goods is expressed in a unit such that, in a given base year $t^{*}$, the prices of the nontradable good and the imported good are equal to each other, $P_{N t^{*}}=P_{M t^{*}}$. This is without loss of generality since the unit of nontradable good being given, it is always possible to define the unit for the imported good so that this condition is satisfied. We thus obtain the ratio $n_{t^{*}} / x_{t^{*}}$ from

$$
\frac{n_{t^{*}}}{x_{t^{*}}}=\frac{G D P_{t^{*}}}{P_{X t^{*}} X_{t^{*}}}-1
$$

Note also that the restriction $P_{N t^{*}}=P_{M t^{*}}$ can be used to determine the value of $\alpha$. Since the CES index (1) implies

$$
\frac{N_{t}}{M_{t}}=\frac{1-\alpha}{\alpha}\left(\frac{P_{N t}}{P_{M t}}\right)^{-\eta},
$$

we can express $\alpha$ as a function of the ratio of nominal expenditures on nontradable goods to nominal expenditures on imports in the base year,

$$
\frac{1-\alpha}{\alpha}=\frac{N_{t^{*}}}{M_{t^{*}}}=\frac{P_{N t^{*}} N_{t^{*}}}{P_{M t^{*}} M_{t^{*}}} .
$$

We use the year $t^{*}=2005$ for the normalization.

We then estimate $\operatorname{AR}(1)$ processes for the series $\left\{x_{t}, n_{t}\right\}$ for each country in our sample. The table below reports the average autocorrelation coefficient and standard deviation in our country sample. More precisely, the table reports the values of $\bar{y}, \rho$ and $\sigma$ from the $\operatorname{AR}(1)$ regression $y_{t}-\bar{y}=\rho\left(y_{t-1}-\bar{y}\right)+\varepsilon_{t}$ where $\sigma^{2}$ is the variance of $\varepsilon$ and $y$ is the column variable. We find that the value of exports in terms of imports is more volatile but less persistent than nontradable output. We also estimate an $\mathrm{AR}(1)$ process for the imports own real rate of interest, $1+r_{t}=\left(1+i_{t-1}\right) /\left(1+\pi_{t}\right)$ where $i_{t}$ is the one-year eurobond interest rate in U.S. dollars. The imports own rate of interest is equal to $3.6 \%$ on average. This interest rate exhibits little persistence and significant volatility because the price of imports is volatile.

The estimated autoregressive processes reported in Table 1 are used to calibrate 
Table 1: Time series properties of state variables

\begin{tabular}{|c|ccc|}
\hline & $x_{t}$ & $n_{t}$ & $r_{t}$ \\
\hline $\bar{y}$ & 0.676 & 1 & $3.56 \%$ \\
$\rho$ & 0.778 & 0.877 & 0.186 \\
$\sigma$ & 0.161 & 0.107 & $12.9 \%$ \\
\hline
\end{tabular}

the model. We approximate each process using the method of Tauchen and Hussey (1991) with five gridpoints for export income and three gridpoints for non-traded income and the real interest rate. ${ }^{6}$

The other parameters in our benchmark calibration are reported in Table 2. The value for risk aversion $(\gamma=2)$ is standard in the literature. The value of $\alpha$ is the crosscountry average of the ratio of nominal expenditures on nontradable good to nominal expenditures on imports in 2005, as explained above. The elasticity of substitution between tradable goods and nontradable goods is set to 1 , a value that is standard in the literature. The growth factor is calibrated to the average growth in nontradable output and in the value of exports in terms of imports in the data. The average growth rates in $n$ and $x$ are respectively $4.3 \%$ and $4.9 \%$ in our sample. In the model these growth rates are assumed to be the same and we set its value to $4.6 \%{ }^{7}$ The value for the discount factor is within the range considered in the literature for models with growth. If the global interest rate were determined by the deterministic steadygrowth path of advanced economies growing at $2 \%$ per year, it would be equal to $1.02^{2} / \beta-1=5.1 \%$. The sensitivity of the results to these parameter values will be discussed in the next section. The benchmark calibration implies that the carry cost of reserves is equal to $\delta=6.9 \%$.

\footnotetext{
${ }^{6}$ The number of gridpoints is not indifferent because the model predictions depend on the lowest value for $x$ in the grid. The Tauchen-Hussey method implies that the lowest point in the grid decreases with the number of gridpoints, and even becomes negative if the number of gridpoints is too large. With five gridpoints the lowest value of $x$ is $70 \%$ below the average level of $x$ under our benchmark calibration. In our country sample the lowest value of $x$ is on average $48 \%$ below $\bar{x}$.

${ }^{7}$ One issue is that the growth rate is higher than the interest rate. This cannot be true forever otherwise the country would not have a well-defined intertemporal budget constraint. The implicit assumption maintained in the rest of the paper is that the growth rate will fall at a distant point in the future. We also experimented with a model where trend growth falls to a lower level with a small probability in every period, and obtained similar results. Although stochastic growth introduces an additional source of risk which could in principle affect the level of precautionary savings, we found this effect to be quantitatively small.
} 
Table 2: Benchmark calibration

\begin{tabular}{|ccccc|}
\hline$\gamma$ & $\alpha$ & $\eta$ & $G$ & $\beta$ \\
\hline 2 & 0.36 & 1 & 1.046 & 0.99 \\
\hline
\end{tabular}

\section{Quantitative Results}

We analyze the quantitative predictions of the model in three steps. First, we look at the model predictions for the target and average levels of reserves. We then consider how reserves optimally adjust in response to shocks. Finally, we analyze the performance of simple linear rules to manage reserves. We report our results using the reserves-to-imports ratio in months, $\rho_{t}=12 * b_{t} / m_{t}$, as this is a standard measure of reserves adequacy. The average reserves-to-imports ratio, $E(\rho)$, is the average value of $\rho$ taken over five thousand 200-period simulations of the model. The target reserves-to-imports ratio, $\rho^{*}$, is the ratio $b^{*} / m^{*}$ where $b^{*}$ and $m^{*}$ are the long-run levels of reserves and imports respectively in the model without shocks.

\subsection{Target and average levels of reserves}

Under our benchmark calibration the average level of reserves $E(\rho)$ is equal to 4.6 months of imports and the target level of reserves $\rho^{*}$ is equal to 3.3 months of imports. The average amount of reserves predicted by the model is quite close to average level of reserves in the data (4.5 months of imports) and the target is close to the 3 -monthsof-imports rule of thumb. This coincidence is remarkable as we did not use any data about reserves to calibrate the model. Is this a fluke, or do plausible calibrations tend to deliver similar results?

Figure 1 shows how the target and average levels of reserves vary with the carry cost $\delta$, risk aversion $\gamma$, the elasticity of substitution $\eta$, and the share of imports in consumption $\alpha$. The average level of reserves is always higher than the target for the reasons explained at the end of section 2.2.

The most important parameter is the carry $\operatorname{cost} \delta$. In Figure 1 we change the carry cost, given the other parameters, by adjusting the discount factor $\beta$. The target and average levels of reserves both decreases with the carry cost. The figure shows the variation of reserves when the carry cost remains above 2 percent. The target level of reserves diverges to infinity as the carry cost goes to zero, and already exceeds 

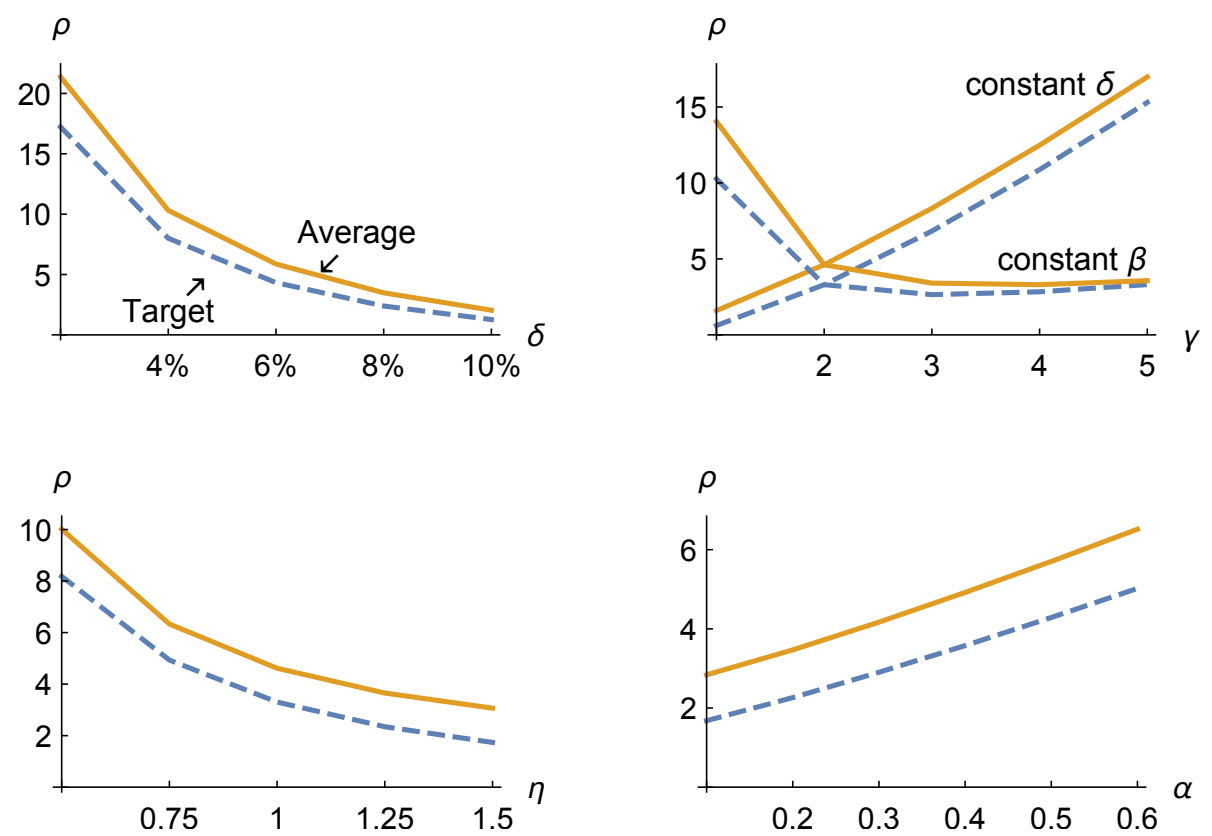

Figure 1: Sensitivity of reserves target $\rho^{*}$ and average reserves $E[\rho]$.

15 months of imports when the carry cost is equal to 2 percent. However under our benchmark calibration the carry cost cannot fall below 5.8 percent if the discount factor $\beta$ stays below 1. For this level of the carry cost the average level of reserves amounts to 6.1 months of imports, and the reserves target to 4.6 months of imports.

We also consider the sensitivity of the target to the risk aversion parameter $\gamma$ that we vary between 1 and 5, a range of values often considered in the literature. The results depend on whether we hold constant the carry $\operatorname{cost} \delta$ or the discount factor $\beta$. If we keep $\delta$ constant by adjusting $\beta$, changes in $\gamma$ capture purely the effect of risk aversion. In this case, higher values of $\gamma$ make the consumer more willing to smooth consumption against shocks and so increase the desired level of reserves. If instead we do not adjust $\beta$, increasing $\gamma$ also makes the consumer less elastic intertemporally, which increases the carry cost of foreign assets and decreases the target. On one hand, increasing $\gamma$ above 2 does not have a significant impact on the optimal level of reserves because the impact of higher risk aversion is offset by that of a lower elasticity of intertemporal elasticity. When $\gamma$ increases the consumer is more willing to hold reserves for insurance but at the same time eager to borrow against future income and these two effects broadly cancel out. On the other hand, reducing risk aversion below 2 significantly increases the optimal level of reserves: the average level 
of reserves increases to almost 15 months of imports if $\gamma$ is equal to 1 .

The reserves target decreases with the elasticity of substitution between tradable and nontradable goods $\eta$. When the two goods are more substitutable the marginal utility of consumption is less sensitive to the consumption of imported goods, which reduces the benefits of precautionary savings. Finally, raising the share of imports in consumption increases the country's exposure to external shocks and so the desired level of reserves.

To conclude, the results from our benchmark calibration are robust in the sense that they are not very sensitive to increasing risk aversion above 2 or changing the consumer's discount rate, as long as it remains positive. However, reducing risk aversion below 2 significantly increases the optimal level of reserves. If $\beta$ and $\gamma$ are both equal to 1 (the combination of values in the plausible set that maximizes the optimal level of reserves), the optimal level of reserves amounts to about 30 months of imports on average.

\subsection{Impulse response functions}

Having analyzed the model implications for the target and average level of reserves, we now turn to the predicted dynamics. Figure 2 shows the impulse response functions of imports and reserves to shocks in export income, nontradable output and the real interest rate. ${ }^{8}$ Imports fall by 20 percent in response to a 30 percent fall in export income because the government runs down reserves by more than one and a half months of imports. Shocks in nontraded output have a smaller impact - a 20 percent fall in nontraded output reduces reserves by about one half of a month of imports. The lowest panel shows the impulse responses to a negative shock in the ex-post imports own real rate of interest. Shocks in this variable reflect mostly unexpected changes in the dollar price of imported goods (there are also shocks in the dollar nominal interest rate, $i_{t}$, but they are much less volatile than shocks in $P_{M t}$ ). An unexpected increase in the price of imports decreases both imports and reserves.

Overall, most of the variation in reserves is explained by shocks to export income rather than the other two variables. Table 3 shows the contribution of each shock to the variance in $b$. For example, the number in the column labeled $x$ is the variance

\footnotetext{
${ }^{8}$ Under our Tauchen-Hussey discretization, the simulated export shock occurs with 22 percent probability, while the nontradable output and real interest rates shocks occur with 17 percent probability.
} 

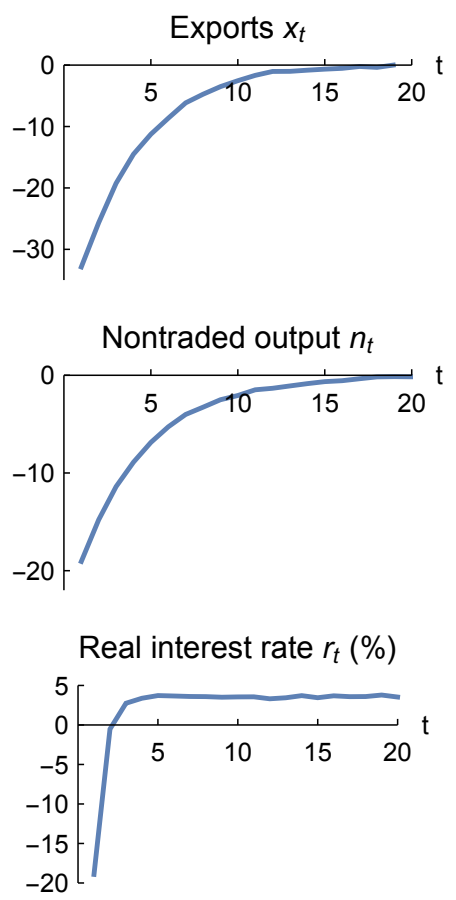

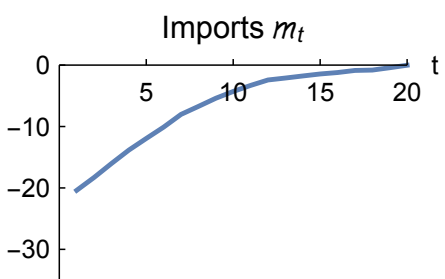

Imports $m_{t}$

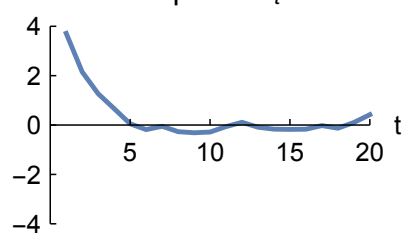

Imports $m_{t}$

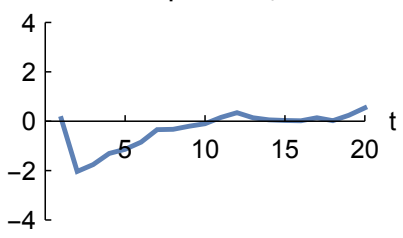

Reserves $\rho_{t}$ (months of $m_{t}$ )
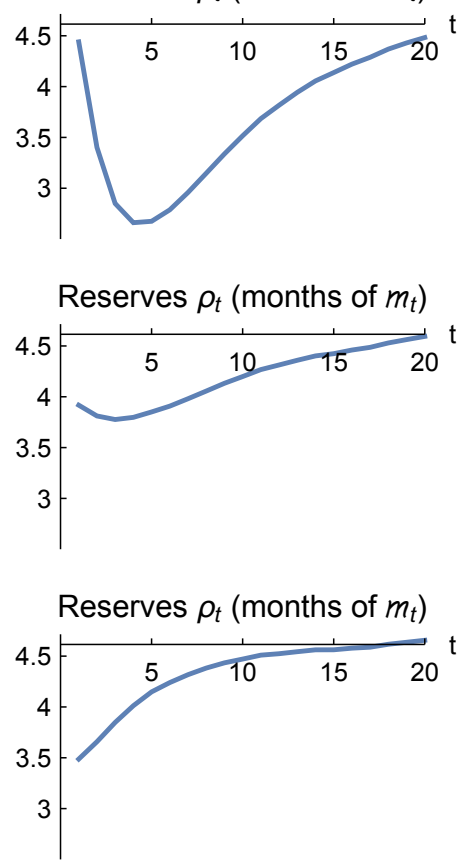

Figure 2: Impulse response functions (\% change if not otherwise specified)

of $b$ in simulations of the model assuming that the only shocks are in $x$ while $n$ and $r$ are set to their average values. The last column reports the variance of $b$ when all three shocks are present. It appears that most of the variance in reserves is explained by the variance in export income $x$.

Table 3: Contributions of the shocks to the variance of reserves

\begin{tabular}{|l|c|c|c|c|}
\hline Shock & $x$ & $n$ & $r$ & $x, n, r$ \\
\hline $\operatorname{Var}(b)$ & 6.866 & 0.287 & 0.257 & 8.660 \\
\hline
\end{tabular}

Finally, we compare in Figure 3 the unconditional distribution of reserves in the model and in the data (left-hand-side and right-hand-side panels respectively). The figure shows the distribution of the ratio of reserves to their average level. In the model reserves spend a substantial amount of time close to the zero lower bound but there is also a relatively fat tail of observations with very high levels of reserves. The figure does not give the visual impression that the government tries to keep reserves close to a target. By contrast reserves stay relatively close to their average level in the data. Governments in the real world seem to be more concerned about keeping 
reserves close to a target than what would seem optimal based on the model. The reluctance of emerging markets and developing countries to run down their reserves in response to bad shocks has been noted in the literature (Aizenman and Sun, 2012). A possible explanation is the fear of sending a bad public signal about the state of the economy.
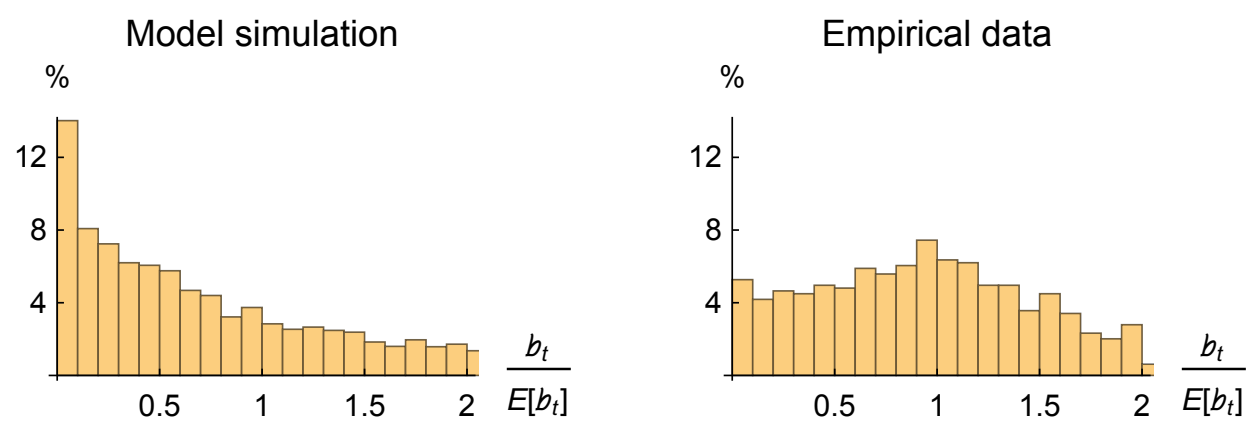

Figure 3: Unconditional distribution of ratio of reserves to average level

\subsection{Linear rules}

The policy function for reserve management predicted by the model is non-linear and therefore difficult to describe as a simple rule of thumb for practitioners. In this section, we look for simple policy rules that deliver most of the welfare gains from optimal reserves management. As shown in the previous section, the model predicts that reserves should be mostly used in response to shocks $x_{t}$. Therefore, we consider a simple linear rule according to which reserves have to converge towards a target $\widehat{b}$ while buffering export shocks $x_{t}$

$$
b_{t}=\frac{1+r_{t}}{1+\bar{r}} b_{t-1}+\lambda\left(x_{t}-\bar{x}\right)+\mu\left(\widehat{b}-b_{t-1}\right) .
$$

The parameter $\lambda$ is the marginal propensity to save export income and the parameter $\mu$ captures the speed of convergence of reserves towards the target $\widehat{b}$. This rule encompasses certainty equivalence as a special case. Certainty equivalence corresponds to the case where there is no reserves target $(\mu=0)$ and the value of $\lambda$ is determined by the fact that imports follow a random walk. In this case reserves $b_{t}$ are nonstationary.

We then look for the values of $\lambda, \mu$ and $\widehat{b}$ that maximize average welfare based on 
a large number of simulations. ${ }^{9}$ Under our benchmark calibration we find

$$
\widehat{b}=0.22, \lambda=0.35, \mu=0.2
$$

Figure 4 illustrates how the optimized linear rule for reserves (dashed lines) compares to the non-linear rule (continuous lines) for alternative values of export income. The linear rule approximates fairly well the non-linear rule when precautionary motives are weaker, i.e., at high levels of export income and reserves. However, there are visible discrepancies when income and reserves are low because the optimal policy function becomes particularly nonlinear.

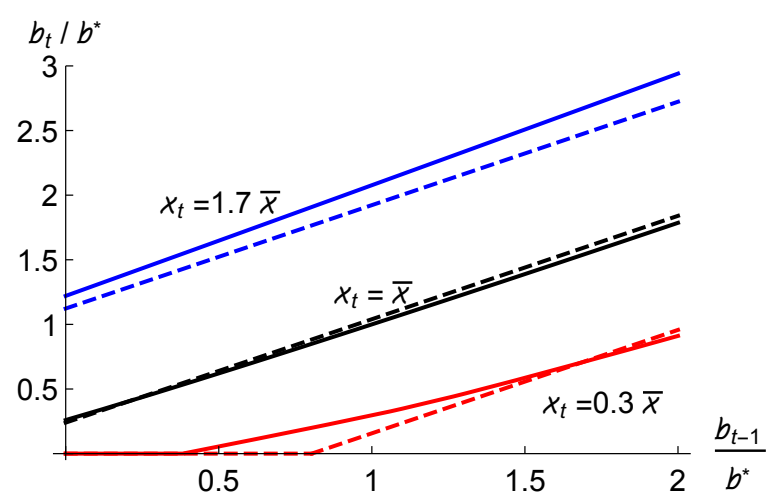

Figure 4: Optimized linear rule for reserves versus non-linear rule.

The optimal target is a little larger than in the non-linear policy (0.22 instead of 0.18). Since a linear rule provides less buffering to shocks, it is thus preferable to hold a somewhat higher stock of reserves. Furthermore, the value for $\lambda$ implies that in any given period the country should accumulate in reserves 35 percent of its export income in excess of the average. This is significantly lower than the value implied by certainty equivalence, which we show in the appendix to be given by

$$
\lambda^{C E}=\frac{\left(1-\rho_{x}\right) G}{1+\bar{r}-\rho_{x} G}
$$

where $\rho_{x}$ is the autocorrelation coefficient in export income. In this formula the growth factor $G$ must be set to $[\beta(1+\bar{r})]^{1 / \gamma}$, the level that makes the consumer

\footnotetext{
${ }^{9}$ More specifically, we run Montecarlo simulations starting from the stochastic distribution of reserves under the non-linear policy functions. These simulations are conducted assuming that countries follow the linear rule (9) for various combinations of the parameters $\{\lambda, \mu, \widehat{b}\}$. Finally, we select the parameters that return the highest average welfare across simulations.
} 
willing to let his consumption increase by the factor $G$ in the deterministic steadygrowth path. Under our benchmark calibration the implied value for the marginal propensity to save is $\lambda^{C E}=0.907$.

Another difference with certainty equivalence is that reserves converge to the target relatively quickly: deviations from the target have a half-life of about three years. This is much quicker than the speed of convergence to the target in calibrated version of models à la Schmitt-Grohé and Uribe (2003). In these models the behavior of foreign assets is essentially the one implied by certainty equivalence except for a weak force that prevents foreign assets from being nonstationary. We find that this is not a good approximation to optimal reserves management in our model.

The reason for the difference with certainty equivalence is that in our model the representative consumer is caught between two strong opposite forces: a strong desire to borrow (because income growth is high) and a strong desire to insure (because export income is volatile). The tension between these two forces lead the consumer to use reserves more sparingly than under certainty equivalence. On the one hand, the propensity to save on a positive export income shock is significantly smaller than under certainty equivalence because the consumer is impatient. On the other hand, the propensity to dissave following a negative export income shock is also smaller than under certainty equivalence because the consumer is reluctant to approach the zero bound on reserves - where there no longer is insurance.

In welfare terms, we find that our optimized linear rule performs well, as it captures most of the welfare gains from reserve management under the non-linear rule. Let us denote by $U_{\max }$ the level of welfare when reserves are used optimally, and by $U_{\min }$ the average level of welfare when reserves are simply set to zero. Optimal reserves management (increasing welfare from $U_{\min }$ to $U_{\max }$ ) has the same impact on welfare as a permanent increase in consumption by 0.57 percent. This is smaller than the welfare gain from turning off the stochastic shocks, which is close to a 5 percent permanent increase in consumption. The latter estimate is larger than typical estimates of the welfare cost from the business cycle because export income is volatile in our sample of developing countries. ${ }^{10}$

Let us denote by $U_{\text {lin }}$ the average welfare under the linear rule. We express the

\footnotetext{
${ }^{10}$ Pallage and Robe (2003) find that removing income and consumption volatility is equivalent to increasing consumption by 12.1 percent in the median country in their sample of developing countries (see their Table 3 for $\theta=\gamma=2$, sample with the US). This is a multiple of the welfare cost of the business cycle in advanced economies as measured by Lucas (1987).
} 

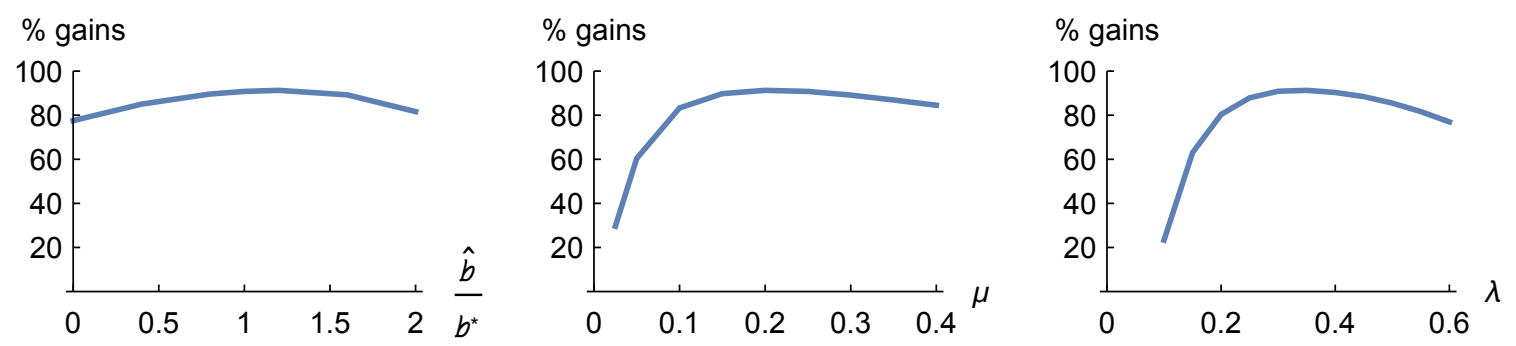

Figure 5: Welfare gains using linear rule for reserves (relative to non-linear rule)

welfare gain from the linear rule as a share of the gain from unconstrained optimal reserves management, i.e., as the ratio

$$
\frac{U_{\text {lin }}-U_{\min }}{U_{\max }-U_{\min }}
$$

We find that the best linear rule provides 91.3 percent of the welfare gains from the best nonlinear rule.

We also consider how the welfare gains from the linear rule vary with the parameters. Contrary to the emphasis that practitioners tend to place on the optimal level of reserves, we find that the precise level of the target $\widehat{b}$ is not very important for welfare. The left chart in Figure 5 shows that welfare under the linear rule is remarkably insensitive to the level of the target $\widehat{b}$ (in the figure the target varies between zero and $\left.2 b^{*}\right)$. It is instead much more important to set the values of $\lambda$ and $\mu$ at the appropriate levels, and especially not to set them too low. This suggests that the level of the target is much less consequential for welfare than how the government accumulates and deccumulates reserves in response to shocks.

The target level $\widehat{b}$ has also minor implications for the optimal values of $\lambda$ and $\mu$. This is illustrated in Figure 6 , which shows that a higher value for $\widehat{b}$ implies only small changes in the optimal levels of $\lambda$ and $\mu$. Therefore, policy makers can focus on the appropriate use of reserves in response to shocks independently of the optimal reserve target.

We also explored whether there are significant welfare gains from asymmetric rules that depend on whether reserves or export income is above or below average, that is

$$
b_{t}=\frac{1+r_{t}}{1+\bar{r}} b_{t-1}+\lambda^{+}\left(x_{t}-\bar{x}\right)^{+}+\lambda^{-}\left(x_{t}-\bar{x}\right)^{-}+\mu^{+}\left(\widehat{b}-b_{t-1}\right)^{+}+\mu^{-}\left(\widehat{b}-b_{t-1}\right)^{-}
$$



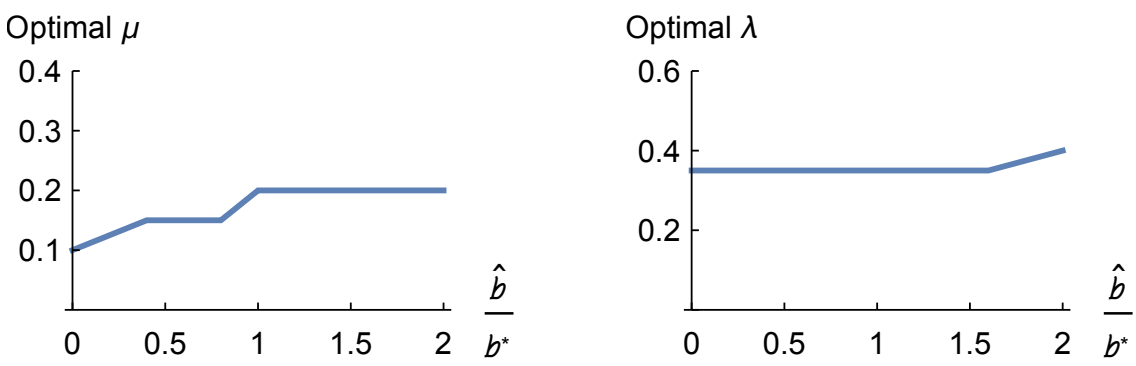

Figure 6: Optimal values for $\lambda$ and $\mu$ given $\widehat{b}$.

We did not find asymmetric rules to be very beneficial for welfare. Allowing for asymmetry in the speed of convergence $\mu$ raises welfare by 0.5 percent of the welfare gains from the best nonlinear rule. Similarly, allowing for asymmetry in $\lambda$ raises welfare by only 0.9 percent of the welfare gains from the best nonlinear rule.

\section{Conclusion}

We presented an intertemporal optimization model to study the optimal management of reserves for financially closed countries facing current account shocks. The fact that the model is welfare-based has allowed us to rigorously define the opportunity cost of reserves and clarify differences with conventional metrics used in the literature. On the quantitative side, we found that plausible calibrations give results that are remarkably close to both the average level of reserves in the data and the 3-monthsof-imports rule of thumb. However, real-world governments seem to be excessively cautious in their use of reserves - the model suggests a more active use of reserves in response to shocks. The welfare gains from reserves management come from using the reserves rather than keeping them close to the target. We also showed that simple linear rules can capture most of the welfare gains from reserve management and thus provide helpful guidance to practitioners. Finally, we pointed out that it is more important to properly adjust reserves in response to shocks than choosing a particular reserve target.

Several directions of research could be pursued in future work. First, it would be interesting to separate risk aversion from the elasticity of intertemporal substitution of consumption by using Epstein-Zin preferences. Second, one could introduce other shocks such as demand shocks in the discount factor. Finally it would be interesting 
to explore how the model can be applied to the optimal management of commodity funds and sovereign wealth funds. 


\section{Appendix: Certainty Equivalence}

We assume that the trend growth rate is consistent with steady-growth path for consumption, i.e.,

$$
G=[\beta(1+\bar{r})]^{1 / \gamma}
$$

We denote with a hat the deviations of the variables from steady state, e.g., $b_{t}=\bar{b}+\widehat{b}_{t}$. The linearization of the budget constraint (2) and the first-order conditions (3) gives,

$$
\begin{gathered}
\widehat{b}_{t}+\widehat{m}_{t}=\widehat{x}_{t}+\frac{\bar{b}}{G} \widehat{r}_{t}+\frac{1+\bar{r}}{G} \widehat{b}_{t-1}, \\
\kappa_{m} \widehat{m}_{t}+\kappa_{n} \widehat{n}_{t}=E_{t}\left(\widehat{r}_{t+1}+\kappa_{m} \widehat{m}_{t+1}+\kappa_{n} \widehat{n}_{t+1}\right),
\end{gathered}
$$

where

$$
\begin{aligned}
\kappa_{m} & =\left(\frac{1}{\eta}-\gamma\right)(\alpha / \bar{m})^{1 / \eta}-1 /(\eta \bar{m}) \\
\kappa_{n} & =\left(\frac{1}{\eta}-\gamma\right)(\alpha / \bar{m})^{1 / \eta}
\end{aligned}
$$

Iterating forward on the budget constraint gives,

$$
b_{t-1}=\frac{G}{1+\bar{r}} E_{t}\left[\sum_{s=0}^{+\infty}\left(\frac{G}{1+\bar{r}}\right)^{s}\left(\widehat{m}_{t+s}-\widehat{x}_{t+s}-\frac{\bar{b}}{G} \widehat{r}_{t+s}\right)\right] .
$$

One can then substitute out the expected terms using $E_{t} \widehat{x}_{t+s}=\rho_{x}^{s} x_{t}, E_{t} \widehat{r}_{t+s}=\rho_{r}^{s} r_{t}$ and

$$
E_{t}\left(\widehat{m}_{t+s}+\frac{\kappa_{n}}{\kappa_{m}} \widehat{n}_{t+s}\right)=\widehat{m}_{t}+\frac{\kappa_{n}}{\kappa_{m}} \widehat{n}_{t}-\frac{\rho_{r}}{\kappa_{m}} \frac{1-\rho_{r}^{s}}{1-\rho_{r}} \widehat{r}_{t}
$$

which is obtained by iterating on the linearized first-order condition. This gives (after tedious manipulations) an expression for linearized imports,

$\widehat{m}_{t}=\frac{1+\bar{r}-G}{1+\bar{r}-\rho_{x} G} \widehat{x}_{t}+\frac{1+\bar{r}-G}{G} \widehat{b}_{t-1}-\frac{\kappa_{n}}{\kappa_{m}} \frac{\left(1-\rho_{n}\right) G}{1+\bar{r}-\rho_{n} G} \widehat{n}_{t}+\frac{\rho_{r} G / \kappa_{m}+(1+\bar{r}-G) \bar{b} / G}{1+\bar{r}-\rho_{r} G} \widehat{r}_{t}$,

and using the linearized budget constraint, for reserves

$$
\widehat{b}_{t}=\widehat{b}_{t-1}+\frac{\left(1-\rho_{x}\right) G}{1+\bar{r}-\rho_{x} G} \widehat{x}_{t}+\frac{\kappa_{n}}{\kappa_{m}} \frac{\left(1-\rho_{n}\right) G}{1+\bar{r}-\rho_{n} G} \widehat{n}_{t}+\frac{\left(1-\rho_{r}\right) \bar{b}-\rho_{r} G / \kappa_{m}}{1+\bar{r}-\rho_{r} G} \widehat{r}_{t}
$$




\section{References}

Aizenman, Joshua, and Yi Sun. 2012. "The financial crisis and sizable international reserves depletion: From fear of floatingto the fear of losing international reserves?" International Review of Economics \&6 Finance, 24: 250-269.

Angeletos, G.M., and V. Panousi. 2011. "Financial Integration, Entrepreneurial Risk and Global Dynamics." Journal of Economic Theory, 146(3): 863-893.

Carroll, Christopher D. 2009. "Theoretical Foundation of Buffer Stock Saving." Unpublished Manuscript, Johns Hopkins University.

Carroll, Christopher D., and Olivier Jeanne. 2009. "A Tractable Model of Precautionary Reserves, Net Foreign Assets, or Sovereign Wealth Funds." NBER Working Paper No. 15228.

Coeurdacier, Nicolas, Hélène Rey, and Pablo Winant. 2011. "The Risky Steady State." The American Economic Review AEA Papers and Proceedings, 101(3): 398-401.

Durdu, Ceyhun Bora, Enrique G. Mendoza, and Marco E. Terrones. 2009. "Precautionary Demand for Foreign Assets in Sudden Stop Economies: an Assessment of the New Mercantilism." Journal of Development Economics, 89: $194-$ 209.

Edwards, S. 1985. "On the Interest-Rate Elasticity of the Demand for International Reserves: Some Evidence From Developing Countries." Journal of International Money and Finance, 4(2): 287-295.

Flood, Robert, and Nancy Marion. 2001. "Holding International Reserves in an Era of High Capital Mobility." Brookings Trade Forum, 1-68.

Fogli, Alessandra, and Fabrizio Perri. 2015. "Macroeconomic Volatility and External Imbalances." Journal of Monetary Economics, 69: 1-15.

Frenkel, Jacob A, and Boyan Jovanovic. 1981. "Optimal international reserves: a stochastic framework." The Economic Journal, 507-514.

Ghosh, Atish R., and Jonathan D. Ostry. 1997. "Macroeconomic Uncertainty, Precautionary Saving and the Current Account." Journal of Monetary Economics, 40(1): 121-139. 
Hamada, Koichi, and Kazuo Ueda. 1977. "Random walks and the theory of the optimal international reserves." The Economic Journal, 722-742.

Hauner, D. 2006. "A Fiscal Price Tag for International Reserves." International Finance, 9(2): 169-195.

Heathcote, Jonathan, Kjetil Storesletten, and Giovanni L Violante. 2009. "Quantitative Macroeconomics with Heterogeneous Households." Annual Review of Economics, 1(1): 319-354.

Heller, Heinz Robert. 1966. "Optimal international reserves." The Economic Journal, 296-311.

IMF. 2011. "Assessing Reserve Adequacy." IMF Policy Paper. Available at www. imf .org/external/np/pp/eng/2011/021411b.pdf.

IMF. 2013. "Assessing Reserve Adequacy_Further Considerations." IMF Policy Paper. Avaliable at www.imf .org/external/np/pp/eng/2013/111313d.pdf.

IMF. 2015. "Assessing Reserve Adequacy-Specific Proposals." Staff Report for the Executive Board. Available at ww. imf.org/external/np/pp/eng/2014/121914. pdf.

Jeanne, Olivier. 2007. "International Reserves in Emerging Market Countries: Too Much of a Good Thing?" Brookings Papers on Economic Activity 2007, 1: 1-79.

Jeanne, Olivier, and Romain Rancière. 2011. "The Optimal Level of Reserves for Emerging Market Countries: Formulas and Applications." Economic Journal, 121(555): 905-930.

Kent, Lance. 2015. "Capital Flows: Convergence vs. Risk." Manuscript, College of Williams and Mary.

Korinek, Anton, and Luis Serven. 2010. "Undervaluation Through Foreign Reserve Accumulation: Static Losses, Dynamic Gains." World Bank Policy Research Working Paper No.5250.

Lucas, Robert E., Jr. 1987. Models of Business Cycles. Basil Blackwell, New York.

Michaud, Amanda, and Jacek Rothert. 2014. "Optimal borrowing constraints and growth in a small open economy." Journal of International Economics, 94(2): 326-340. 
Pallage, Stephane, and Michel A. Robe. 2003. "On the Welfare Cost of Business Cycles in Developing Countries." International Economic Review, 44(2): 677-98.

Rabe, Collin. 2013. "A Welfare Analysis of 'New Mercantilist' Foreign Asset Accumulation." Manuscript, Johns Hopkins University.

Rodrik, D. 2006. "The Social Cost of Foreign Exchange Reserves." International Economic Journal, 20(3): 253-266.

Sandri, Damiano. 2014. "Growth and Capital Flows with Risky Entrepreneuship." American Economic Journal: Macroeconomics, 6(3): 102-23.

Schmitt-Grohé, Stephanie, and Martín Uribe. 2003. "Closing Small Open Economy Models." Journal of International Economics, 61(1): 163-185.

Tauchen, George, and Robert Hussey. 1991. "Quadrature-Based Methods for Obtaining Approximate Solutions to Nonlinear Asset Pricing Models." Econometrica, 59(2): 371-396. 